\title{
Determination of Bolton Norms for Indian Population Sample
}

\author{
Dr TV Pavan Kumar,' Dr Prasad Chitra² \\ 'Resident, 2 Professor, Dept of Orthodontics, Army College of Dental Sciences, \\ Secunderabad, India
}

Correspondence: Dr. TV Pavan Kumar; Email: drtvpavan5321@gmail.com

\section{ABSTRACT}

Introduction: Tooth size discrepancy varies between different ethnic groups and races. Bolton's tooth size norms were originally determined in Caucasian population.

Objective: To determine tooth size ratios for maxillary and mandibular dentition in Telangana population of Indian sample and to compare the ratios with standard Bolton norms.

Materials \& Method: The study sample comprised of 300 subjects ( 150 males and 150 females) aged between 14-25 years having Angle's Class 1 molar relationship. Study models of all subjects were prepared and mesiodistal dimensions were measured to determine mean Bolton's anterior ratio, overall ratio, over jet and overbite.

Result: Evidence of sexual dimorphism was observed with Indian male subjects having greater mean values than the females. The determined mean for anterior tooth ratio was $80.88 \pm 3.03 \%$, overall tooth ratio $93.99 \pm 3.11 \%$, overjet $2.92 \pm 0.62 \mathrm{~mm}$ and overbite $2.96 \pm 0.63 \mathrm{~mm}$. Statistically significant differences were found between Indian samples and Bolton Caucasian standards

Conclusion: The study provides evidence that tooth sizes are population specific. Mean values specific to particular population groups should be derived in order to make treatment planning more accurate and predictable.

Key words: Bolton's analysis, Bolton's ratio, study model analysis, tooth size discrepancy

\section{INTRODUCTION}

The hardest tissues in the human body comprise of teeth, which help in mastication, phonation and also provide a vital esthetic component to the face on visualization.' As literature reveals, whenever teeth are properly arranged in maxillary and mandibular arches with muscular forces acting in harmony, it is observed that the occlusion is healthy, stable and esthetically attractive. The size of the teeth plays a very important role in overall treatment planning. Mismatched tooth sizes prevent the clinician from achieving balanced and functional occlusion. Understanding the interplay between arch length and tooth material is the key to overall treatment success. Tooth size, arch form and its dimensions, spacing and tooth size - arch length discrepancies should be accurately determined as a part of routine orthodontic treatment planning. According to Proffit, although natural teeth have a good ratio in most individuals, part of the population (5\%) has some degree of disproportion in tooth size. $^{2}$

Disproportion in the mesiodistal dimensions of teeth of opposing dental arches can be defined as tooth size discrepancy. Generally, "contact methods" like Vernier scales with calipers or millimeter rulers are used to measure mesiodistal tooth dimensions.3.4 Some "noncontact methods" less frequently used included television images, ${ }^{5}$ dental cast prints ${ }^{6}$ and occlusal surface laser holograms. ${ }^{7.8}$ Sterophotogrammetry ${ }^{9}$ and Optocom ${ }^{10}$ are advances in computer technology available today for three dimensional cast visualization. Black ${ }^{11}$ was one of the first investigators to study tooth size, and measured the mesiodistal tooth dimensions on a large scale. Bolton ${ }^{12}$ in 1958 postulated on tooth size disharmony which remains one of the most accepted studies till date.

Studies for specific populations to determine tooth ratios have been conducted in the past. Lundstrom ${ }^{13}$ in 1964 found significant differences amongst populations for tooth size ratios which in turn could affect incisor inclinations, interincisal angle, overbite and overjet. Differences in tooth size ratios for Caucasoid, Mongoloid and Negroid populations were evaluated in another study by Lavelle ${ }^{14}$ who determined that overall and anterior ratios were greater in Negroids as compared to Caucasoids with the Mongoloids showing intermediate readings.

Crosby and Alexander ${ }^{15}$ found no differences in incidence rates among different groups but observed that subjects 
within each group showed tooth size discrepancies greater than 2 standard deviations from the Bolton mean. Lew and Keng ${ }^{16}$ found no differences in tooth size ratios for the anterior teeth which closely matched the original Bolton standards in Chinese population.

Hashim et $\mathrm{al}^{17}$ concluded that the Sudanese population closely matched the Caucasian figures. However, they mentioned that the population of Sudan comprised of several racial groups with differing features making conclusions difficult. Analysis of Bolton tooth size ratios among Qatari population by Hashim et al ${ }^{18}$ showed similarities in overall Bolton ratio, while significant differences were observed in anterior ratio.

Hashim and Murshid ${ }^{19}$ investigated tooth size ratios in Saudi population with varying malocclusions. No differences in anterior and overall ratio were evident when compared to Bolton standards. The study provided evidence that malocclusions in general do not affect tooth size ratios.

Variations in labiolingual crown thickness and the possible changes in Bolton analysis were investigated by Rudolph et al. ${ }^{20}$ They determined a formula which considered labiolingual thickness in predicting anterior tooth size discrepancies. Individuals with thin incisors showed stronger correlation with intermaxillary ratios as compared to thick teeth.

Nie and Lin $^{21}$ studied Chinese population to compare intermaxillary tooth size discrepancies amongst different malocclusion groups for both sexes. There was a significant difference in tooth size ratios where Class III groups had higher mean values than Class I and Class II.

An analysis of two databases PubMed and Cochrane Review revealed only one study till date in the Indian context evaluating Bolton ratios in North Indian population with varying malocclusions. The results showed that Class II subjects had a tendency for greater mesiodistal widths in the mandibular anterior region as compared to maxillary anterior region.

Evidence in literature about varying tooth sizes in populations and the need to formulate population specific Bolton norms formed the primary reason for the study. The objectives of the study is to determine tooth size discrepancy of clinical significance in a representative sample of Indian population sample of Telangana State and to formulate Bolton norms which could be used in population specific treatment planning. The values determined through the study would also be compared with standard Bolton norms.

\section{MATERIALS AND METHOD}

The study was designed as an observational ex vivo type to determine Bolton's tooth size ratios for Indian population of Telangana state. A total of 1200 subjects were screened out of which 500 subjects fulfilled the required inclusion criteria. 300 subjects $(150$ males and 150 females) were randomly selected from this. The inclusion criteria were: subjects of Indian origin, Class 1 molar and canine relationship bilaterally, permanent teeth from first to first molar in both arches, normal overjet and overbite relation, curve of Spee not exceeding $1.5 \mathrm{~mm}$, no proximal restorations or caries on any teeth.

The parameters evaluated in the study were the overjet, overbite, anterior and overall Bolton tooth ratios. Alginate impressions were made for all subjects and study models were prepared. A digital Vernier caliper with a sensitivity of $0.1 \mathrm{~mm}$ was used to obtain mesiodistal measurements of the teeth.

The results obtained were subjected to statistical analysis which included t test to compare mean values between males and females and chi square test for determining associations between various variables.

\section{RESULT}

The overjet, overbite, anterior and overall tooth ratios for Telengana Indian population samples are depicted in Table 1. The gender-wise comparison for anterior tooth ratio, overall tooth ratio, overjet and overbite showed that except overall tooth ratio; male norms were greater than in females (Table 2). A comparison of values for Indian sample and Caucasian measurements is given in Table 3.

Table 1: Norms for overjet, overbite, anterior tooth ratio \& posterior tooth ratio

\begin{tabular}{|c|c|c|c|c|}
\hline Parameters & Range & Mean & Std. deviation & Variance \\
\hline Overjet & 2.00 & 2.92 & 0.61 & 0.37 \\
\hline Overbite & 2.00 & 2.96 & 0.63 & 0.39 \\
\hline Anterior ratio & 28.40 & 80.88 & 3.03 & 9.23 \\
\hline Overall ratio & 16.40 & 93.99 & 3.11 & 9.71 \\
\hline
\end{tabular}


Table 2: Gender comparison for overjet, overbite, anterior tooth ratio \& posterior tooth ratio

\begin{tabular}{|c|c|c|c|c|c|}
\hline Parameters & Male (Mean $\pm S D$ ) & Female (Mean $\pm S D)$ & Mean difference & t-Value & $p$-Value \\
\hline Overjet & $2.98 \pm 0.65$ & $2.86 \pm 0.56$ & 0.123 & 1.747 & 0.082 \\
\hline Overbite & $3.01 \pm 0.65$ & $2.91 \pm 0.60$ & 0.096 & 1.330 & 0.185 \\
\hline Anterior ratio & $81.46 \pm 3.15$ & $80.31 \pm 2.80$ & 1.155 & 3.348 & $0.001^{*}$ \\
\hline Overall ratio & $93.27 \pm 2.38$ & $94.71 \pm 3.57$ & 1.432 & 4.084 & $0.001^{*}$ \\
\hline
\end{tabular}

*Statistically significant at $p \leq 0.001$

Table 3: Comparison of parameters among Indian and Caucasian populations

\begin{tabular}{|c|c|c|c|c|}
\hline Parameters & Indian Mean & Caucasian Mean & Variation & p-Value \\
\hline Anterior Ratio & $80.88 \pm 3.03$ & $77.2 \pm 1.65$ & 9.23 & $0.0001^{*}$ \\
\hline Overall Ratio & $93.99 \pm 3.11$ & $91.3 \pm 3.11$ & 9.71 & $0.0001^{*}$ \\
\hline Overjet & $2.92 \pm 0.62$ & $1.92 \pm 0.63$ & 0.62 & $>0.05$ (NS) \\
\hline Overbite & $2.96 \pm 0.63$ & $2.45 \pm 0.81$ & 0.63 & $>0.05$ (NS) \\
\hline
\end{tabular}

NS: Not significant

\section{DISCUSSION}

Orthodontists should pay special attention to the presence of tooth size discrepancy because about $60 \%$ of orthodontic patients present with an anterior Bolton discrepancy. ${ }^{12}$ Failure to identify this disparity can invariably create difficulties for finishing cases, especially in regard to the ideal relationship of molars and canines and obtaining ideal overjet and overbite. ${ }^{13,22}$

Crosby and Alexander 15 reported Bolton means for anterior (77.2\%) and overall (91.4\%) ratios as similar to those of Bolton and Stifter. Similar results were seen by Mahankudo et al in Karnataka population with anterior ratio $77.78 \%$ and overall ratio $92.005 \% .{ }^{23}$ The mean overall ratio in Spanish population was $91.97 \%,{ }^{24}$ Turkish population was $89.88,{ }^{25}$ Dominican Americans was $91.3 \%,{ }^{26}$ white Americans was $92.3 \%^{27}$ and Peruvians was $91.3 \%{ }^{28}$ From these studies, it can be concluded that Bolton's overall tooth ratio cannot be applied to all populations.

The results suggest that the overall tooth ratio for Indian population sample is higher than white Americans followed by Spanish, Peruvians and Turkish. These results are similar to Smith et al; who showed significant differences in overall and anterior ratios between Whites, Blacks, and Hispanics. ${ }^{27}$ Uysal and Sari urged the need for separate anterior and overall tooth ratio means in Turkish population. ${ }^{25}$

According to the present study, Indian males have greater anterior ratio as compared to females in similarity to
Richardson and Malhotra who found that Black North American males had larger teeth than females. ${ }^{29}$ Hashim et al also concluded that tooth size ratios were slightly greater in males than in females in Qatari population. ${ }^{18}$ Bishara et al among lowa, Egypt and Mexico populations reported sexual dimorphism. Further, they mentioned that canines and molars were significantly larger in males. ${ }^{30}$

\section{CONCLUSION}

1. Mean values for Telangana population of Indian samples were determined as:

- Anterior tooth ratio: $80.88 \pm 3.03 \%$

- Overall tooth ratio: $93.99 \pm 3.11 \%$

- Overjet: $2.92 \pm 0.62 \mathrm{~mm}$

- Overbite: $2.96 \pm 0.63 \mathrm{~mm}$

2. The comparison between male and female samples suggests sexual dimorphism in tooth measurements. Males were found to have significantly greater mean values than females.

3. Collating the mean anterior and overall ratio of Indian population samples with that of Caucasian Bolton's values resulted in statistically significant differences. However, overjet and overbite showed no significant differences. 


\section{REFERENCES}

1. Merz M, Isaacson R, Germane N, Rubenstein L. Tooth diameters and arch perimeters in a black and a white population. Am J Orthod Dentofacial Orthop. 1991; 100(1):53-8.

2. Ricci, Ivan Delgado. Bolton ratio in subjects with normal occlusion and malocclusion. Braz J Oral Sci. 2013; 12:4:357-61.

3. Nance HN. The limitations of orthodontic treatment; diagnosis and treatment in the permanent dentition. Am J Orthod. 1947; 33:253-301.

4. Ballard ML. Asymmetry in tooth size, a factor in the etiology, diagnosis and treatment of malocclusion. Angle Orthod. 1944; 14:67-71.

5. Brook AH, Pitts NB, Renson CE. Determination of tooth dimensions from study casts using an image analysis system. J Int Assoc Dent Child. 1983; 14:55-60.

6. Singh IJ, Savara BS. A method for making tooth and dental arch measurements. J Am Dent Assoc. 1964; 69:719-21.

7. Keating PJ, Parker RA, Keane D, Wright L. The holographic storage of study models. Br J Orthod. 1984; 11:119-25.

8. Martensson B, Ryden $\mathrm{H}$. The holodent system, a new technique for measurement and storage of dental cast. Am J Orthod Dentofacial Orthop. 1992; 102:113-9.

9. Burke PH, Beard FH. Stereophotogrammetry of the face. A preliminary investigation into the accuracy of a simplified system evolved for contour mapping by photography. Am J Orthod. 1967; 53:769-82.

10. Van der Linden FP, Boersma H, Zelders T, Peters KA, Raaben JH. Three-dimensional analysis of dental casts by means of the optocom. J Dent Res. 1972; 51:1100.

11. Black GV. Descriptive anatomy of the human teeth. 4th ed. Philadelphia S.S. White Dental; 1902.

12. Bolton W. A disharmony to tooth size and its relation to the analysis and treatment of malocclusion. Angle Orthod 1958; $28: 113-30$.

13. Lundstom A. Tooth size and occlusion in twins. Thesis (Uppsala) Karger, Basle;1964.

14. Lavelle CL. Maxillary and mandibular tooth size in different racial groups and different occlusal categories. Am J Orthod 1972; 61:29-37.

15. Crosby D, Alexander $C$. The occurrence of tooth size discrepancies among different malocclusion groups. Am J Orthod Dentofacial Orthop. 1989; 95(6):457-61.

16. Lee KK, Keng SB. Anterior crown dimensions and relationship in an ethnic Chinese population with normal occlusions. Aus Orthod J. 1991 12(2):105-9.

17. Abdalla Hashim AH, Eldin AH, Hashim HA. Bolton tooth size ratio among Sudanese Population sample: A preliminary study. J Orthod Sci. 2015; 4(3):77-82.

18. Hashim HA, Hayder A, Najah AL-Sayed, Hashim AL-Hussain. Bolton tooth size ratio among Qatari population sample: An odontometric study. J Orthod Sci. 2017; 6(1):22-7.

19. Hashim HA, Murshid ZA. Mesiodistal tooth width in a Saudi population sample comparing right and left sides. Part 2. Egypt Dent J. 1993: $39(1): 347-50$

20. Rudolph DJ, Dominguez PD, Ahn K, Thinh T. The use of tooth thickness in predicting intermaxillary tooth-size discrepancies. Angle Orthod. 1998; 68(2):133-8.

21. Nie Q1, Lin J. Comparison of intermaxillary tooth size discrepancies among different malocclusion groups. Am J Orthod Dentofacial Orthop. 1999; $116(5): 539-44$.

22. Araujo E, Souki M. Bolton anterior tooth size discrepancies among different malocclusion groups. Angle Orthod. 2003; 73(3):307-13.

23. Mahankudo, Ganesh. Measurements of Bolton's tooth width ratios in Karnataka population: A preliminary study. Br J Med Med Res. 2016; 14:2:1-5.

24. Paredes V, Williams F, Cibrian R, Williams F, Meneses A and Gandia J. Mesiodistal sizes and intermaxillary tooth-size ratios of two populations; Spanish and Peruvian. A comparative study. Med Oral Patol Oral Cir Bucal. 2011; 16(4):593-9.

25. Uysal T, Sari Z. Intermaxillary tooth size discrepancy and mesiodistal crown dimensions for a Turkish population. Am J Orthod Dentofacia Orthop. 2005; 128(2):226-30.

26. Santoro M, Ayoub ME and Pardi V. Mesiodistal crown dimensions and tooth size discrepancy of the permanent dentition in Dominican Americans. Angle Orthod. 2000; 70:303-7.

27. Smith S, Buschang P, Watanabe E. Interarch tooth size relationships of 3 populations: Does Bolton's analysis apply? Am J Orthod Dentofacial Orthop. 2000; 117(2):169-74

28. Major PW, Flores-Mir C. Tooth-width ratio discrepancies in a sample of Peruvian adolescents. Am J Orthod Dentofac Orthop. 2004; 125(3):361-5

29. Richardson E, Malhotra S. Mesiodistal crown dimension of the permanent dentition of American Negroes. Am J Orthod. 1975; 68(2):15764.

30. Bishara S, Jakobsen J, Abdallah E, Fernandez Garcia A. Comparisons of mesiodistal and buccolingnal crown dimensions of the permanent teeth in three populations from Egypt, Mexico, and the United States. Am J Orthod Dentofacial Orthop. 1989; 96(5):416-22. 